\title{
МОДЕЛИРОВАНИЕ МАТЕРИАЛА ЦИЛИНДРИЧЕСКОЙ ЗАГОТОВКИ СО СВАРНЫМ ШВОМ ПРИ ОБЖИМЕ-РАЗДАЧЕ
}

Раздача концов трубных заготовок сопровождается потерей устойчивости в окружном и осевом направлении, а также локализацией деформаций с последующим разрушением в виде образования продольной трещины, зарождающейся на торце заготовки $[1,2]$. Наличие сварного шва усложняет условия деформирования при обжиме-раздаче и приводит к разрушению заготовки по сварному шву [3, 4]. Для предотвращения трещинообразования необходимо ужесточать коэффициенты обжима-раздачи, что неизбежно приводит к увеличению количества переходов, трудоемкости процесса и себестоимости изготовления детали в целом.

Надежных аналитических методов определения напряженно-деформированного состояния при раздаче заготовок со сварным швом на сегодняшний день не существует. Имеются разрозненные данные, которые учитывают наличие сварного шва с помощью коэффициентов усиления, где зона термического влияния и сам сварочный шов имеют более высокие прочностные и пластические характеристики по сравнению с основным металлом заготовки [5]. Также имеются численные решения, в которых в явном виде сложно оценить факторы, влияющие на разрушение сварной конструкции [6-8], где показано, что в основном, механические свойства сварных соединений напрямую зависят от ширины поверхности сварного шва и морфологии перехода между свариваемыми пластинами.

Вопрос деформирования сварных конструкций вызывает интерес с развитием новых материалов для автомобилестроения, таких как соединения двух или более стальных листов с различными механическими свойствами, толщиной или типом покрытия, которые имеют большое значение для снижения веса, минимизации затрат и сокращения брака [9-11].

Целью работы является разработка метода моделирования материала при раздаче цилиндрической заготовки со сварным швом коническим пуансоном, что позволит, учитывая механические характеристики зоны термического влияния, расширить возможности деформирования.

Наличие сварного шва в цилиндрической заготовке приводит к неопределенности физико-механических характеристик материала, который подвергается холодной пластической деформации. Учет начальной анизотропии металла не позволяет в полной мере определить особенности механических характеристик в зоне наложения сварного соединения, где данные параметры изменяются скачкообразно в тангенциальном направлении $[12,13]$. Это приводит систему основной металл-сварной шов к совместной пластической деформации в условиях однородного нагружения, однако, величина деформаций зависит уже от пластических свойств каждого составляющего системы. Поэтому расчетные зависимости для коэффициентов обжима-раздачи, пригодные для цельных заготовок, зачастую становятся неработоспособными для сварных конструкций. Так, например, в колесном производстве при изготовлении ободьев колес заготовкой является стальная сварная обечайка (рис. 1). Первой операцией при их радиально-ротационном профилировании служит раздача торцов цилиндра с двух сторон. Для уменьшения интенсивности деформирования на последующих переходах профилирования с целью обеспечения минимальной разнотолщинности обода следует увеличивать степень деформации при раздаче заготовки. Варьирование коэффициентами раздачи в сторону их ступенчатого повышения позволяет приблизить форму полуфабриката для первого перехода профилирования к готовому профилю заданного сечения, что значительно уменьшает локализацию деформаций в радиусных сопряжениях. Однако, как показывают эксперименты, приближение коэффициентов раздачи к предельным невозможно из-за наличия сварного соединения. 


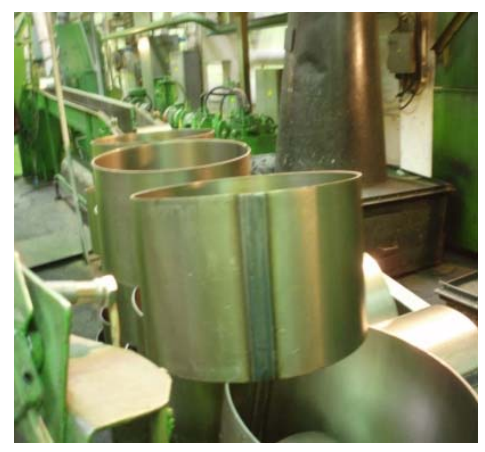

a

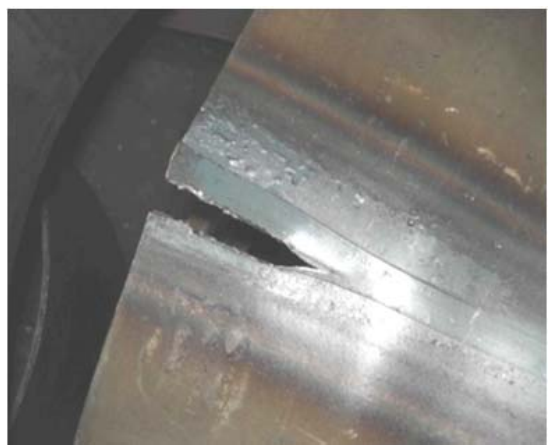

6

Рис. 1. Сварная обечайка (а) и ее деформация раздачей с разрушением по сварному шву (б)

В расчетные коэффициенты вводится поправка на сварной шов. Поправочные коэффициенты, применяемые в расчетах, получены на основе опыта производства и практически не изменяются при раздаче заготовок различных геометрических размеров и марок сталей. То есть, не учитываются особенности деформирования каждой партии заготовок, теряется индивидуальность подхода к проектированию технологического процесса профилирования и, как следствие, удлиняется цикл производства и увеличивается технологическая себестоимость. Коэффициенты раздачи принимаются в пределах 1,05-1,1, что значительно ниже рекомендуемых при обжиме-раздаче трубных заготовок [16, 17]. Поэтому разработка метода расчета напряженно-деформированного состояния сварной заготовки с учетом физико-механических характеристик сварного шва является актуальной задачей не только для колесного производства, но также для машиностроительной отрасли в целом.

Для схематизации процесса раздачи примем, что цилиндрическая оболочка деформируется под действием внедрения пуансона в заготовку, причем она состоит из основного металла и узкой вставки металла с измененными механическими свойствами, имитирующей сварной шов. Причем составляющие конструкции соединены между собой жестко, без зазоров и деформируются одновременно с момента нагружения до прекращения действия сил $[14,15]$. Моделирование металла заготовки ведем по аналогии с рекомендациями [18]. шит работу:

При сжатии-растяжении цилиндрической оболочки осевой силой, последняя совер-

$$
A_{l}=P \Delta l,
$$

где $P$ - осевая сила (Н); $\Delta l$ - изменение высоты цилиндра (м).

Однако:

$$
\Delta l=\varepsilon l=\frac{P l}{F E_{x}}=\frac{P l}{2 \pi R s E_{x}},
$$

где $E_{x}$ - секущий модуль в осевом направлении (МПа); $R$ - радиус серединной поверхности цилиндра (м); $s$ - толщина стенки заготовки (м); $l$ - высота цилиндрической заготовки (м).

Тогда:

$$
A_{l}=\frac{P^{2} l}{2 \pi R s E_{x}} .
$$

При раздаче происходит сжатие недеформируемой части заготовки усилием деформирования $P$. Эта сила воспринимается оболочкой в целом, но так как она состоит из материалов с разными механическими свойствами, то можно предположить, что часть этой силы воспринимается основным металлом и часть металлом сварного шва. При этом сила совершит работу: 


$$
A_{2}=P_{o c H} \Delta l_{o c H} \pm P_{u в} \Delta l_{m \varepsilon},
$$

где $P_{\text {осн}}, P_{\text {шв }}$ - усилие, которое воспринимается основным металлом и полоской сварного шва $(\mathrm{H}) ; \Delta l_{\text {осн }} \Delta l_{\text {шв }}$ - изменения высоты цилиндра по основному металлу и по сварному шву (м).

Знак «+» в вышестоящей формуле применяется в том случае, когда металл шва и околошовной зоны имеет повышенные механические характеристики по сравнению с основным металлом и знак «-» в обратном случае.

По аналогии с (2):

$$
\begin{aligned}
& \Delta l_{u в}=\varepsilon_{u \varepsilon} l=\frac{P_{u \varepsilon} l}{F_{u в} E_{u в}} ; \\
& \Delta l_{\text {ocH }}=\varepsilon_{\text {ocH }} l=\frac{P_{\text {ocH }} l}{F_{\text {ocH }} E_{\text {ocH }}},
\end{aligned}
$$

где $\varepsilon_{\text {шв}}, F_{\text {шв }}, E_{\text {шв }}$ - относительная деформация, площадь поперечного сечения и секущий модуль металла сварного шва; $\varepsilon_{\text {осн }}, F_{\text {осн }}, E_{\text {осн }}$ - относительная деформация, площадь поперечного сечения и секущий модуль основного металла цилиндрической заготовки.

Тогда работа деформации будет равна:

$$
A_{2}=\left(\frac{P_{u в}^{2}}{F_{u в} E_{u в}} \pm \frac{P_{o c H}^{2}}{F_{o c H} E_{o c H}}\right) l .
$$

Должно выполняться равенство $A_{1}=A_{2}$ или:

$$
\frac{P^{2}}{2 \pi R s E_{x}}=\frac{P_{u в}^{2}}{F_{u в} E_{u в}} \pm \frac{P_{o c H}^{2}}{F_{o c H} E_{o c H}} .
$$

Из схематизации процесса нагружения очевидно, что $P_{o c н}+P_{u в}=P$ и принимая равенство изменений высот $\Delta l_{o c н}=\Delta l_{\text {шв }}$, получим:

$$
\begin{gathered}
P_{u в}=\frac{F_{u в} E_{u в}}{F_{o c H} E_{o c H}} \frac{P}{1 \pm \frac{F_{u b} E_{u b}}{F_{o c H} E_{o c H}}}, \\
P_{o c H}=\frac{P}{1 \pm \frac{F_{u b} E_{u в}}{F_{o c H} E_{o c H}}} .
\end{gathered}
$$

Подставим значения усилий $P_{\text {шв }}$ и $P_{\text {осн }}$ в $(6)$ и будем иметь:

$$
E_{x}=E_{o c H}\left(1 \pm \frac{E_{u в}}{E_{o c H}} \frac{F_{u в}}{2 \pi R s}\right)
$$

Аналогичные преобразования оформим относительно секущего модуля в тангенциальном направлении.

При определении жесткости в окружном направлении можно исходить из предположения, что оболочка находится под действием равномерного внутреннего давления $q$, которое производит работу:

$$
\grave{A_{1}}=q \Delta V,
$$


где $\Delta V$ - приращение объема оболочки, равное:

$$
\Delta V=\left\lfloor\pi(R+w)^{2}-\pi R^{2}\right\rfloor \approx 2 \pi R l w .
$$

Ho

$$
\varepsilon=\frac{w}{R}=\frac{\sigma_{y}}{E_{y}}=\frac{q R^{2}}{E_{y} s},
$$

откуда

$$
w=\frac{q R^{2}}{E_{y} S} .
$$

Тогда

$$
\Delta V=\frac{2 \pi R^{3} l q}{E_{y} s} .
$$

Следовательно

$$
A_{1}=\frac{2 \pi R^{3} l q^{2}}{E_{y} s}
$$

В случае оболочки со сварным швом давление $q$ совершает работу:

$$
A_{2}=q_{о б} \Delta V_{\text {об }} \pm S_{\text {щв }} \Delta l_{\text {шв }},
$$

где $S_{\text {щв }}=q_{m \varepsilon} a_{m \varepsilon} R-$ сила, приходящаяся на сварной шов; $a_{m \varepsilon}-$ длина сварного шва;

$$
\begin{gathered}
\Delta V_{\text {об }}=\left[\pi(R+w)^{2}-\pi R^{2}\right]=\frac{2 \pi R^{2} l q}{E_{y} s}, \\
\Delta l_{u в}=\frac{q_{u в} a_{u в} R}{F_{u в} E_{u в}} 2 \pi R .
\end{gathered}
$$

Тогда

$$
A_{2}=\frac{2 \pi R^{3} l q_{o \sigma}^{2}}{F_{o \sigma} S} \pm \frac{2 \pi m R^{3} a_{u в}^{2} q_{u в}^{2}}{E_{u в} F_{u в}}
$$

Как и в первом случае, должно быть $A_{1}=A_{2}$. Кроме того,

$$
q_{\text {шв}}+q_{\text {об }}=q, \varepsilon_{\text {об }}=\varepsilon_{\text {шв }} .
$$

Опуская все промежуточные выкладки, представим окончательный результат:

$$
E_{y}=E_{\text {об }}\left(1 \pm \frac{E_{u в} F_{u в}}{E_{\text {об }} a_{u в} s}\right) .
$$




\section{ВЫВОДЫ}

Полученные уравнения для секущих модулей в меридиональном и тангенциальном направлении показали, что деформирование трубной заготовки будет зависеть не только от характеристик пластичности основного металла и металла сварочного шва, что очевидно, но также от соотношения площадей трубной заготовки. Из данных соотношений следует, что приведенные секущие модули изменяются по сравнению с начальным модулем пластичности изотропной заготовки в обоих направлениях. Возрастание приведенных модулей пластичности сопровождается упрочнением сварного соединения по сравнению с начальным металлом заготовки, соответственно уменьшение величины секущего модуля в обоих направлениях - понижением прочностных характеристик металла шва. Дальнейший анализ деформирования сварной заготовки необходимо проводить с учетом локальной анизотропии, вызываемой сварочным швом, что даст возможность определить условия устойчивой пластической деформации и создать дополнительное воздействие на ослабленный участок.

\section{СПИСОК ИСПОЛЬЗОВАННОЙ ЛИТЕРАТУРЫ}

1. Попов Е.А. Основы теории листовой штамповки. Москва: Машиностроение. 1977. 278 с.

2. Пузырь Р.Г. Пузырь Р.Г., Троцко О.В., Черкащенко В.Ю. Влияние геометрических параметров цилиндрической заготовки на напряженно-деформированное состояние при раздаче коническими пуансонами. Обработка материалов давлением. Краматорск: ДГМА. 2012. 4(33). С. 114-121.

3. Аверкиев Ю.А., Аверкиев А. Ю. Технология холодной штамповки. Москва : Машиностроение. 1989. 304 с.

4. Драгобецкий В.В., Бойко Ю.А., Пузырь Р.Г. Описание процесса формоизменения сварных заготовок. Вісник КДПУ ім. Михайла Остроградського. 2008. 2. С. 79-83.

5. Яковлев С.П., Кухарь В.Д. Штамповка анизотропных материалов. Москва: Машиностроение. 1986.136 с.

6. Мороз Н.Н., Драгобецкий В.В., Бойко Ю.А. Предельная степень деформации при расчете сварных цилиндрических заготовок для изготовления ободьев колес. Вісник КДПУ ім. Михайла Остроградського. 2009.6. C. $63-65$.

7. Qiu X.G., Chen W.L. The study on numerical simulation of the laser tailor welded blanks stamping. Journal of Materials Processing Technology. 2007, 187, pp. 128-131. DOI: https://doi.org/10.1016/j.jmatprotec.2006.11.128

8. Mohebbi M.S., Akbarzadeh A. Prediction of formability of tailor welded blanks by modification of MK model. International Journal of Mechanical Sciences. 2012, 61(1). pp. 44-51.

9. Puzyr R., Haikova T., Trotsko O., Argat R. Determining experimentally the stress-strained state in the radial rotary method of obtaining wheels rims. Eastern European Journal of Enterprise Technologies. 2016,1 pp. 52-60.

10. Puzyr R., Savelov D., Argat R., Chernish A. Distribution analysis of stresses across the stretching edge of die body and bending radius of deforming roll during profiling and drawing of cylindrical workpiece. Metallurgical and Mining Industry. 2015, 1, pp. 27-32.

11. Драгобецький В.В., Левченко Р.В., Пузырь Р.Г. Анализ нагружения заготовки при радиальноротационном способе получения ободьев колес с измененной схемой внешнего воздействия. Обработка материалов давлением. Краматорск: ДГМА. 2012. 1(30). С. 146-149.

12. Пузырь Р.Г., Мосьпан Д.В., Драгобецкий В.В. Определение потребного крутящего момента при радиально-ротационном профилировании ободьев колес. Вісник КДПУ ім. Михайла Остроградського. Кременчук. 2008. 6. C. 64-66.

13. Пузырь Р.Г. Расчет компонент тензора напряжений на втором переходе радиально-ротационного профилирования ободьев колес транспортных средств. Обработка материалов давлением. Краматорск: ДГМА. 2016. 1(42). С. 164-168.

14. Пузырь Р.Г., Долгих О.Н., Гриценко Б.С., Дикая Л.Э. Распределение напряжений на коническом участке профиля полуфабриката первого перехода радиально-ротационного профилирования. Bicнuк KHУ iм. Михайла Остроградського. Кременчук. 2015. 39. С. 67-73

15. Пузырь Р.Г., Дикая Л.Э. Учет упрочнения металла при определении зоны возможной кольцевой потери устойчивости на первой операции раздачи при изготовлении ободьев колес. Вісник ХНТУ. Херсон. 2015.3. C. $165-169$.

16. Сосенушкин Е.Н., Яновская Е.А., Хачатрян Д.В., Смолович И.Е., Киндеров В.Ю. Анализ процесса раздачи трубных заготовок при штамповке изделий с коническими поверхностями. Обработка материалов давлением. Краматорск: ДГМА. 2013. 2(35). С. 135-141.

17. Калюжный А.В., Пиманов В.В., Олександренко Я.С., Куликов И.П. Интенсификация процесса раздачи осесимметрических трубчатых заготовок. Обработка материалов давлением. Краматорск: ДГМА. 2014.1. C. $103-108$.

18. Авдонин А.С. Прикладные методы расчета оболочек и тонкостенных конструкцій. Москва: Машиностроение. 1969. 405 с. 


\section{REFERENCES} (in Russian).

1. Popov E.A. Fundamentals of the theory of sheet stamping. Moscow: Mechanical Engineering. 1977, 278 p.

2. Puzyr R.G., Trotsko O.V., Cherkaschenko V.Yu. Influence of the geometrical parameters of a cylindrical billet on the stress-strain state during distribution by conical punches. Materials Working by Pressure. Kramatorsk: DSEA. 2012, 4(33), pp. 114-121. (in Russian).

3. Averkiev Yu.A., Averkiev A.Yu. Technology of cold stamping. Moscow: Mechanical Engineering. 1989, 304 p. (in Russian).

4. Dragobetsky V.V., Boyko Yu.A., Bubble R.G. Description of the process of shaping welded billets. Bulletin of the KSPU M. Ostrogradsky. 2008, 2, pp. 79-83. (in Russian).

5. Yakovlev S.P., Kukhar V.D. Stamping of anisotropic materials. Moscow: Mechanical Engineering. 1986. 136 p. (in Russian).

6. Moroz N.N., Dragobetsky V.V., Boyko Yu.A. The ultimate degree of deformation in the calculation of welded cylindrical billets for the manufacture of wheel rims. Bulletin of the KSPU M. Ostrogradsky. 2009, 6, pp. 63-65. (in Russian).

7. Qiu X.G., Chen W.L. The study on numerical simulation of the laser tailor welded blanks stamping. Journal of Materials Processing Technology. 2007, 187, pp. 128-131. DOI: https://doi.org/10.1016/j.jmatprotec.2006.11.128

8. Mohebbi M., Akbarzadeh A. Prediction of formability of tailor welded blanks by modification of MK model. International Journal of Mechanical Sciences. 2012, 61(1), pp. 44-51.

9. Puzyr R., Haikova T., Trotsko O., Argat R. Determining experimentally the stress-strained state in the radial rotary method of obtaining wheels rims. Eastern European Journal of Enterprise Technologies. 2016, 1, pp. 52-60.

10. Puzyr R., Savelov D., Argat R., Chernish A. Distribution analysis of stresses across the stretching edge of die body and bending radius of deforming roll during profiling and drawing of cylindrical workpiece. Metallurgical and Mining Industry. 2015, 1, pp. 27-32.

11. Dragobetsky V.V., Levchenko R.V., Puzyr R.G. Analysis of the loading of a workpiece with a radial-rotational method for producing wheel rims with a modified external action pattern. Materials Working by Pressure. Kramatorsk: DSEA. 2012, 1(30), pp. 146-149. (in Russian).

12. Puzyr R.G., Mospan D.V., Dragobetsky V.V. Determination of the required torque for radial-rotational profiling of wheel rims. Bulletin of the KSPU M. Ostrogradsky. Kremenchuk. 2008, 6, pp. 64-66. (in Russian).

13. Puzyr R.G. Calculation of the components of the stress tensor at the second transition of the radial-rotational profiling of the rims of the wheels of vehicles. Materials Working by Pressure. Kramatorsk: DSEA. 2016, 1(42), pp. 164- 168. (in Russian).

14. Puzyr R.G., Dolgikh O.N., Gritsenko B.S., Dikaya L.E. Distribution of stresses on the conical section of the semi-finished product profile of the first transition of radial-rotational profiling. Bulletin of the KNU M. Ostrogradsky. Kremenchuk. 2015, 39, pp. 67-73. (in Russian).

15. Puzyr R.G., Dikaya L.E. Accounting for the hardening of metal in determining the zone of possible annular loss of stability in the first distribution operation in the manufacture of wheel rims. Bulletin of the KhNTU. Kherson. 2015, 3, pp. 165-169. (in Russian).

16. Sosenushkin E.N., Yanovskaya E.A., Khachatryan D.V., Smolovich I.E., Kinderov V.Yu. Analysis of the process of distribution of pipe billets during stamping of products with conical surfaces. Materials Working by Pressure. Kramatorsk: DSEA. 2013, 2(35), pp. 135-141. (in Russian).

17. Kalyuzhny A.V., Pimanov V.V., Oleksandrenko Ya.S., Kulikov I.P. Intensification of the process of distribution of axisymmetric tubular billets. Materials Working by Pressure. Kramatorsk: DSEA. 2014, 1(38), pp. 103- 108. (in Russian).

18. Avdonin A.S. Applied methods for calculating shells and thin-walled structures. Moscow: Mechanical Engineering. 1969, 405 p. (in Russian).

Пузырь Р. Г. - - д-р техн. наук, доц. КрНУ им. М. Остроградского;

Драгобецкий В. В. - д-р техн. наук, проф. КрНУ им. М. Остроградского;

Левченко Р. В. - канд. техн. наук ККрНУ им. М. Остроградского;

Сирая Ю. Б. $\quad$ - аспирант ККрНУ им. М. Остроградского.

КрНУ - Кременчугский национальный университет имени Михаила Остроградского, г. Кременчуг;

ККрНУ - Колледж Кременчугского национального университета имени Михаила Остроградского, г. Кременчуг.

E-mail: puzyruslan@gmail.com; 